\title{
Correspondence
}

\section{Respiratory arrest after recovery from anaesthesia supplemented with sufentanil}

To the Editor:

I wish to report a case of acute respiratory arrest following apparently satisfactory recovery from general anaesthesia supplemented with sufentanil.

The patient was a 61-year-old, $68 \mathrm{~kg}$ female presenting for hemicolectomy. She was premedicated with oxazepam $30 \mathrm{mg}$ PO and morphine $8 \mathrm{mg}$ IM 90 minutes before surgery. Thiopentone $100 \mathrm{mg}$, sufentanil $150 \mu \mathrm{g}$ and succinylcholine $120 \mathrm{mg}$ were administered IV and the trachea was intubated. The patient was ventilated with nitrous oxide 60 per cent and oxygen 40 per cent and pancuronium $4 \mathrm{mg}$ was administered lV. Thirty minutes later, following the surgical incision, sufentanil $25 \mu \mathrm{g}$ was administered in response to increases in pulse and blood pressure. Isoflurane $0.25-0.5$ per cent was added in response to similar responses to surgical stimulation. At the end of surgery pyridostigmine $20 \mathrm{mg}$ and atropine 1.2 $\mathrm{mg}$ werc administered IV. One hundred and sixty-five minutes after anaesthetic induction the patient was awake and extubated herself in the operating room.

When the patient was transferred to the recovery room she was breathing well, oriented and talking to the anaesthetist. In the recovery room, ten minutes following extubation, the patient's vital signs were normal, including respiratory rate of $18 \cdot \mathrm{min}^{-1}$. She was conscious, oriented and talking with the nurses. Fifteen minutes following extubation the patient was noted to be apnoeic, cyanotic and unresponsive to commands or deep pain.

The patient responded immediately to the administration of naloxone $0.2 \mathrm{mg} \mathrm{IV}$ and within 60 seconds she was awake, breathing spontaneously and responding appropriately. Her subsequent course was uneventful.

Respiratory depression after anaesthesia with a narcotic is well recognized. The rapidity with which this patient became apnoeic and the depth of narcosis was unusual. Chang et al. ${ }^{1}$ reported a similar case of post-anaesthetic respiratory depression with associated chest wall rigidity following sufentanil, while Goldberg et al. ${ }^{2}$ described a more gradual onset of respiratory depression, again associated with chest wall rigidity. Both reports concluded that the use of moderately high doses of sufentanil (2-5 $\mu \mathrm{g} \cdot \mathrm{kg}^{-1}$ ) as a supplement to anaesthesia could be associated with significant respiratory depression in the early postoperative periud. In this dose range, the duration of respiratory depression produced by sufentanil is said to be comparable to that seen with fentanyl. In our department, where fentanyl is the most commonly used narcotic, we had never experienced such profound postoperative renarcotisation.

The pharmacokinetics of sufentanil were found by Bovill et al, ${ }^{3}$ to be similar to fentanyl in having a three compartment open model characterised by triexponential decay. The third compartment acts as a reservoir, limiting return of the drug to the central compartment from which elimination is assumed to occur.

Becker $e t$ at. ${ }^{4}$ observed respiratory depression in the postoperative period after fentanyl anaesthesia. He found a consistent decrease in the slope of the carbon dioxide response curve. This in itself would not be surprising but these authurs also described a recurrence of respiralory depression in the recovery room, after normality had apparently been achieved. Following this report, secondary peaks in plasma fentanyl levels were subsequently observed. Stoeckel et al. ${ }^{5}$ noted high initial plasna fentanyl concentrations following a bolus dose IV and in many patients a secondary increase in plasma concentration was seen. McQuay et al. ${ }^{6}$ demonstrated a second peak of fentanyl in the plasma of many patients.

McClain and $\mathrm{Hug}^{7}$ suggested that the cumulation and persistence of fentanyl may cause unexpectedly prolonged ventilatory depression. Recurrent respiratory depression might result from mobilisation of fentanyl from tissue stores and from reduced stimulation.

The recommended induction dose of sufentanil for major surgery with an anticipated duration of two hours is $1.5-2.0 \mu \mathrm{g} \cdot \mathrm{kg}^{-1}$. Maintenance doses of $10-25 \mu \mathrm{g}$ are given, based on changes in clinical signs. Total dose requirements should average $1 \mu \mathrm{g} \cdot \mathrm{kg}^{-1} \cdot \mathrm{hr}^{-1}$. Respiratory depression produced by a sufentanil dose of $25 \mu \mathrm{g}$ IV is said to last 25-30 minutes.

Our patient received $2.6 \mu \mathrm{g} \cdot \mathrm{kg}^{-1}$ for a 2.5 -hour procedure, with the last increment being administered 120 minutes prior to the end of the procedure and 140 minutes before the respiratory arrest.

The manufacturer of sufentanil warns: "Patients who arrive in the recovery room awake and alert may lapse into a sedated state with diminished breathing if left unstimulated." Our patient by comparison was comatose and apnoeic, presumably due to a secondary narcotic peak. 
The probable explanation is that with increased muscle tone, voluntary movement and increased body temperature there was increased perfusion of skeletal muscle with re-uptake by the blood of sufentanil and increased plasma concentration. Stimulation during emergence and transfer to the recovery room may antagonise the ventilary depressant effects of residual low-dose sufentanil and respiratory depression may only become evident when the patient is relatively unstimulated in the postoperative period.

\author{
D. Robinson, MB, FRCPC, FFARCS \\ Department of Anaesthesia \\ St. Paul's Hospital \\ Vancouver, British Columbia V6Z 1Y6
}

\section{REFERENCES}

1 Chang J, Fish $K J$. Acute respiratory arrest and rigidity after anesthesia with sufentanil: a case report. Anesthesiology 1985; 63: 710-1.

2 Goldberg M, Ishak S, Gorcia C, McKenna J. Post-operative rigidity following sufentanil administration. Anesthesiology 1985; 63: 199-201.

3 Bowill JG, Sebel PS, Blackbum CL, Oei-Lim V, Heykants JJ. The pharmacokinetics of sufentanil in surgical patients. Anesthesiology 1984; 61: 502-6.

4 Becker LD, Paulson BA, Miller RD, Severinghaus, JW, Eger El II. Biphasic respiratory depression after fentanyldroperidol or fentanyl used to supplement nitrous oxide anesthesia. Anesthesiology 1976; 44: 291-6.

5 Stoeckei H, Hengstmant JH, Schutler J. Pharmacokinetics of fentanyl as a possible explanation for recurrence of respiratory depression. Br J Anaesth 1979; 51: 74I-4

6 McQuay HJ, Moore RA, Panerson GMC, Adams AP. Plasma fentanyl, fentanyl concentration and clinical observations during and after operation. Br I Anaesth 1979; 51: $543-50$.

7 McClain DA, Hug CC. Intravenous fentanyl kinetics. Clin Pharmacol Ther 1980; 28: 106-14.

\section{Airway assessment in obstetrical patients}

To the Editor:

After reading Dr. McIntyre's article on difficult tracheal intubation, ${ }^{1}$ I would like to emphasize that any anaesthetist dealing with pregnant patients should assess their airway with the patient recumbent. In this position, large pendulous breasts will often rise up to rest under the chin and thus make both constant cricothyroid pressure and tracheal intubation difficult, if not impossible. Taping the breasts out of the way and/or use of a short handled (Datta) laryngoscope or a laryngoscope with a "polio blade" may facilitate intubation.

Obstetrical emergencies often require anaesthetizing a patient who has recently ingested a full meal. The risk of encountering a difficult or failed intubation as well as pulmonary aspiration of excessively acid gastric material is much greater in the pregnant patient. ${ }^{2,3}$ Careful preoperative airway assessment may help to prevent these potential disasters.

Peggy L.E. Ross MD BsC(Meds) FRCPC

Depurtment of Araesthesia

Grace Hospital and University of British Columbia

4490 Oak \$treet

Vancouver, British Columbia Y6H 3V5

\section{REFERENCES}

1 Mclntyre JWR. The difficult tracheal intubation. Can $\mathrm{J}$ Anaesth 1987; 34: 204-13

2 Tomkins $I$, Turnbull A, Rabson $G$ et al. Report on Confi dential Enquiries into Matemal Deaths in England and Wales. 1976-1978. Department of Health and Social Security, Her Majesty's Stationery Office. 1982.

3 Gibbs CP. Maternal Physiology. Clin Obstet Gynecol 1981; 24: 538

\section{$R E P L Y$}

One purpose of the article was to emphasise the value of a careful preanaesthesia exumination regarding potential difficulties of tracheal intubation. From this viewpoint the problems that may be presented by the pregnant patient do not differ substantially from certain others such as the very obese person. As for the position in which the patient is examined, Dr. Ross's point is weil taken and it is reasonable to state that any patient should be examined in the position in which intubation will be attempred. Other matters she mentions, though vitally important, fall within the realm of selecsion of anaesthesia conditions and state of consciousness under which intubation is done rather than the technique of intubation.

J.W.R. Mclntyre MD FRCPC Dcpartment of Anacsthesia University of Alberta Hospitals Edmonton, Alberta T6G 2B7

\section{Facial nerve paralysis following mask anaesthesia}

To the Editor:

The incidence of facial nerve paresis following mask anaesthesia is rare. Azar and Lear' and Glauber ${ }^{2}$ in 1986, described three patients who developed sensory and motor nerve dysfunction of the face, following mask 